\title{
Study on Traditional Ethnic Chess Games in Gansu Province: The Cultural Connotations and Values
}

\author{
Ying'an Wang1, Xiaoming $\mathrm{Ma}^{1 *}$, Tao Shang ${ }^{2}$ \\ ${ }^{1}$ College of Physical Education, Qinghai Nationalities University, Xining, China \\ ${ }^{2}$ Tibetan Chess Association, Lhasa, China \\ Email: ^592707294@qq.com
}

How to cite this paper: Wang, Y. A., Ma, X. M., \& Shang, T. (2021). Study on Traditional Ethnic Chess Games in Gansu Province: The Cultural Connotations and Values. Advances in Physical Education, 11, 276-283. https://doi.org/10.4236/ape.2021.112023

Received: February 19, 2021

Accepted: May 17, 2021

Published: May 20, 2021

Copyright $\odot 2021$ by author(s) and Scientific Research Publishing Inc. This work is licensed under the Creative Commons Attribution International License (CC BY 4.0).

http://creativecommons.org/licenses/by/4.0/

\begin{abstract}
Traditional ethnic chess games are inseparable part of Chinese culture. From the perspective of intangible culture, this paper analyzes the principles and cultural characteristics of Square chess and Jiu chess, and studies their historical origins, playing rules and structures. It also elaborates the value and role of traditional ethnic chess games in this day and age.
\end{abstract}

\section{Keywords}

Traditional Ethnic Chess Games, Square Chess, Jiu Chess, Cultural Values

\section{Introduction}

Traditional board games of chess and Go have a long history in China, and popularize in various ethnic areas for its easy playing features. They could not only carry the ethnic spirit and values, but also reflect the corresponding ethnic cultural characteristics. Among traditional minority ethnic sports in Gansu province, there exists a kind of chess, which is rich in contents and varied in categories. Among them, "Jiu chess" (Jiu Qi) and "Square chess" (Fang Qi) are the most distinctive, regarded as an indispensable part of the intangible cultural heritage of ethnic sports in Gansu. Nowadays, the influence of traditional board games gradually weakens and even has disappeared in some regions, resulting in unprecedented difficulties for the inheritance of traditional ethnic chess. This situation worsens as people are changing in the outlook on the world, life, and values with the improving standards of living, and easily distracted by other novel and exciting things. In some areas, it is rare to see the scene of ethnic minorities playing chess. 
Traditional ethnic culture is extensive and profound, considered as the deepest spiritual memory of the whole nation. However, the traditional chess culture is endangered on the verge of being lost, and has seen a decline of many excellent categories. If a nation loses its traditional culture, it is just like a building that has lost its foundation, let alone a firm standing in the long river of history. According to the findings of some scholars, for many traditional ethnic chess games, very few people could have the opportunity to watch in the areas outside the ethnic groups, even rare to see in the ethnic areas. Due to various historical reasons, these traditional ethnic chess games are currently on the verge of dying, and urgent measures are required for saving and protecting. Therefore, many scholars have conducted in-depth research to ensure that these precious traditional ethnic cultures could be saved ${ }^{1}$. But there is very little research on connotations and values of Gansu traditional ethnic chess culture. In this case, constructive efforts should be made on protecting and recording chess manuals and structures of the most representative chess games, namely Square chess and Jiu chess. Square chess, commonly known as "Xia Fang", has an origin in Ningxia and is popular among Hui people in northwest China. It has been listed as the regional intangible cultural heritage in Ningxia Hui Autonomous Region. Jiu chess, same as Square chess, is also prevailing in northwest China and has been rated as Tibetan regional intangible cultural heritage. There exist various categories of traditional chess games in northwest China, which have been attached great significance by local governments at present. For Tibetan chess, its classification could even be traced back to the inheritors. In September 2019, Tibetan chess showed its face in the $11^{\text {th }}$ National Traditional Games of Ethnic Minorites as the exhibition sport program, and won the third prize, marking the point that local ethnic chess game finally on a national arena. At the same time, these chess games have popularized in ethnic areas of Gansu to a large scale. Therefore, for the purpose of demonstrating the cultural values embedded in these traditional ethnic chess games, this paper tries to conduct related research based on historical materials, unearthed culture relics, visits and investigations.

\section{Main Categories of Gansu Ethnic Chess Games}

Gansu traditional chess games are considered as an inseparable part to that of the Chinese culture. Since ancient times, traditional chess culture has been widely spread in ethnic minority areas. Chess and Go, usually mentioned together with other traditional art forms as Guqin and painting, have witnessed thousand years of history in China. As the popular board games involving battle of wits, they integrate philosophy, poetry, art and many other contents, not only

${ }^{1}$ The research on the protection of Gansu chess culture in recent years includes: LI Wentong. Research on Study on the Development Status and Countermeasures of Weiqi Association of Ordinary Colleges and Universities in Gansu Province. Master's thesis, Lanzhou University of Technology, 2018; MA Xiaoming, ZHOU Xiaoli. Reflections on the Study of Tibetan Chess. Qinghai Journai of Ethnology, 2016; GAO Jike, LI Bin, LI Fawei. Study on the Culture of Board Games in Han Rhapsody. Proceedings of the Symposium on Sports Science in Gansu, 2014; KONG Desheng. Facing Three Dilemmas: Chinese Chess in Gansu, Lanzhou Daily, 2005. 
showing the thinking and intelligence of two sides, but also demonstrating vividly a kind of humane temperature of tranquility, wit and open-mindness. These board games could embody the idea of harmony between man and nature, and also highlight many philosophy thoughts, which greatly enriches the connotation of these board games. As to the chess, groups of pieces intertwine across the border of two opposing powers; as to the Go game, two players, black and white, take turns placing the stones aiming to win the most points of territory. This paper will focus on Square Chess and Jiu Chess, the most popular categories in Gansu, (Jiu chess featured by its rich varieties), in order to better display the charm of traditional ethnic chess culture and its humanistic values.

\subsection{Categories and Origins of Gansu Traditional Chess Games}

There are abundant chess games prevailing in Gansu, mainly for entertainment or competitive purposes. Among them, Square chess is a featured competitive one. Regarding its origin, after reviewing a large number of local chronicles and documents, no conclusive evidence was found to prove where it came from. It is worth mentioning that some archaeologists in Ningxia found a brick with vertical and horizontal lines in a Han dynasty tomb in Zhongning County, making people easily think of Square chess (Pan \& Ding, 2008). It was later proved as an ancient folk chess game, and could be related to the origin of Square chess. The moves and rules of Square chess vary in Gansu, Qinghai, Shaanxi, Xinjiang, Ningxia and other provinces.

Although the origin of Tibetan chess is still not conclusive, scholars believe that there are two possibilities for the origin. One is that Go originated in the interior areas and then spread to Tibet, while retaining rules of ancient Go; the other is that it originated in the Bon religion period of Tibet, used for divination and mantra. However, there are scholars believe that it originated in Tibet and interior areas separately (Ma \& Shang, 2017b). So it is difficult to reach a consensus.

\subsection{The Current Situation of Chess in Gansu Province}

The traditional chess culture in Gansu Province is rooted in the native culture of ethnic minorities. It is the crystallization of national wisdom, the treasure of Chinese culture and an integral part of minority communities. But with the rapid development of economic opening and modernization, people's lifestyle is changing unawares. Many traditional chess games are gradually fading away, together with the invasion of online chess games and the curiosity of people about new things, the fine culture of Chinese traditional chess in the past thousand years has been neglected, and many traditional chess cultures are on the verge of extinction. Besides, only old people are still playing these games, which makes urgent protecting measures essential.

\subsection{The Development of Representative Chess Games}

On April 16 $6^{\text {th }}$ 2011, the First Mongolian Chess Competition was held in Subei 
Mongol Autonomous County of Gansu Province, which attracted many Mongolian Chess lovers, men and women, old and young. The event went very well. It has not only promoted exchanges among various ethnic groups, but also becomes a common folk custom, cultural and physical activity, greatly enriching the people's spiritual and cultural life. As to the promotion of other categories of chess games, there is still room for improvement in scale and influence.

Square chess, since included in the $2^{\text {nd }}$ Traditional Games of Ethnic Minorities in Ningxia Hui Autonomous Region since 1986, has been listed in the $7^{\text {th }} \mathrm{Na}$ tional Traditional Games of Ethnic Minorities held in Ningxia in 2003 (Pan \& Ding, 2008). However, the promotion scale in Gansu province is far from satisfactory.

\section{The Principles and Characteristics of Square Chess and Jiu Chess in Gansu Province}

\section{Playing Rules of Square Chess and Jiu Chess}

1) Characteristics of Square Chess

Usually, in their spare time, people in northern China often set up a chessboard, and use Go stones to play, so as to enjoy the pleasure of "battle of wits". Throughout the development of chess culture, Square chess has a long history. Initially popular in the northern rural areas, it is well-received by ethnic minorities. As a matter of fact, the figure of Square chess can be seen in cultural works of Hui Muslim, and popular poetry, for example, a traditional ballad goes, "Sing a Hua'er and have a game of Square chess, to relieve brother's distraught ... (Han \& Han, 2007)".

Square chess not only inspires wisdom but also adds spice to life. Normally, people gather together after meal or labor to play it. It does not need as many people as other sports do, and is not subject to site constraint. As long as there is a space, people can draw a board with a branch on the ground and begin to entertain themselves.

The board pattern of Square chess is similar to that of Go. It is made up of 7 horizontal lines and 7 vertical lines $(7 \times 7$ grid), forming squares of same size. But different from other chess games, the number of points (intersections) of Square chess is odd, which is 49 and the number of stones one possesses is one more than the other (Wang, 2013). Using a tool to draw a $7 \times 7$ grid and taking tiles, pebbles, broken bricks or silver coins replacing black and white stones, two players can start a game. The first player has 25 stones, normally takes the initiative and has a greater chance of winning, while the opposing player has 24 stones. In the process, both sides try to see through each other's strategy, and respond flexibly according to the moves, which makes the game unpredictable, perplexing, changeable and full of fun and excitement. Jargons of Square chess include "Touma", "Wuhuazi", "Liujiaozi", etc. with complicated skills and changing positions. Usually, the players start to move stones after all of them are on the board and when one side constructs a square with 4 adjacent stones, he/she can capture the other's stones in the square until they are all taken away. 
It is saying that the square formed is called "Che", with which one's fighting capability will be enhanced and winning rate increased. If a player constructs "Bei Che" or "Tie Che (Han, 2011)", his/her defending and attacking ability will be much strengthened, and is harder to conquer.

2) Characteristics of Jiu Chess

The term "Jiu" is transliterated from Tibetan, expressing the meaning of "jigsaw puzzle" (Ma \& Shang, 2017a). Different from Square chess, Jiu chess is mainly composed of the layout in the opening, capture in the middle game, and keima (knight's move) in the endgame, with unpredictable strategies throughout the fighting. Mainly rising in Qinghai, Gansu, and other Tibetan areas in China, Jiu chess, like other sports, is of rich competitiveness. Actually, based on Jiu Chess, there are other types of chess derived from it, such as Jiaqi (clamp chess) in Qinghai and Zhanqi (battle chess) in Nei Monggol, from which we may conclude that Jiu chess is the most outstanding representative. Even for Checkers, with hundreds of millions of fans, the playing rule is still of extreme similarity to that of Jiu chess.

Tibetan Chess in Gansu has a long history. According to the existing historical records, Tibetan chess was born and thrived in Tibetan areas as far back as the Songtsen Gampo period. In 1995, from the relics of ancient Guge Kingdom (from $9^{\text {th }}$ to $17^{\text {th }}$ century) in western Tibet Ngari, archaeologists excavated a $25 \times$ $15 \mathrm{~cm}$-sized chessboard with a grid of 17 horizontal and 17 vertical lines (Dargye \& Ding, 2012), which undoubtedly proves the long history of Tibetan chess. According to the existing literature, many scholars agree to divide Tibetan chess into two types: the large and the small. The large one is with the same playing rule as that of Go, while the small one is with a relatively small chessboard of $9 \times$ 9 and 32 stones held by each player. Before opening, both players place 16 stones in a fixed position (adjacent side) on the chessboard, and take alternate turns to move the stone. During the game, if the player captures the opponent's stone, the prisoner (captured stone) on the chessboard shall be replaced with his/her stone. At the end of the game, the player with the most stones left on chessboard wins. Different from Square chess, even if a skill gap exists, both players could adopt the method of compensation point instead of handicap to ensure the fairness of the game. In general, the number of compensation points shall be decided by the players through negotiation.

\section{Cultural Connotations and Values of Traditional Ethnic Chess}

\subsection{Cultural Connotations of Traditional Ethnic Chess}

Square chess, with a deep mass basis, is highly praised as entertainment by people in northwest China. Those chess masters, often considered as intellectuals, are highly respected by local people. The playing rule is to move stones in an interactive way following the horizontal and vertical lines, and more moves are allowed when there is no other block until the building of a small "square", 
namely the one-sided territory. Its board is usually a $7 \times 7$ grid with 49 points. Although it is easy to comprehend the playing rule, the essence is still difficult to grasp. It usually takes at least 20 minutes for a game, neither as accurate to seconds as chess, nor is it like Go, ranging from one hour to three or four hours. When playing Square chess, through a constantly changing situation, players should not only focus on the attack for defeating the opponent, but also claims particular care to defense for safeguarding the array of one's own not to be easily broken. As a traditional sport of Hui Muslim (Islam), Square chess is common in rural areas.

Jiu chess is of rich entertainment and competition. Unlike other types of chess games, instead of specifying clearly the use and level of stones, Jiu chess keeps its stones of equal status. During the game, Jiu chess has no differentiated camp and battle area for players, but let them move the stones flexibly according to the changing situation. In other words, the battle situation between the two sides could reverse or overturn due to the different positions of each moving stone. As a symbol of chess culture, Jiu chess reflects the ethnical culture of tribal equality and nomadic culture of living by water and grass, fully demonstrating the pursuit of the spiritual and cultural characteristics of simpleness, elegance, and humor.

\subsection{Cultural Values of Traditional Ethnic Chess}

Both Square chess and Jiu chess can never develop well without the cultural influence of Han nationality, since their existence more than 1000 years ago. The culture of Han nationality has played a vital role in the formation of ethnic regional culture. The Tubo (ancient Tibet) Period in the Tang Dynasty was a critical period for the rapid development of Tibet's politics, economy, and culture. In the $15^{\text {th }}$ year of the Zhenguan reign (641 A.D.) of the Tang Dynasty, Songtsen Gampo, the renowned king of the Tubo Regime, intermarried with Princess Wencheng, which initiated the cultural exchanges between Zang (Tibetan) and Han nationalities. Then in the $4^{\text {th }}$ year of Jinglong reign (710 A.D.) of Tang Emperor Zhongzong, the marriage between Princess Jincheng and the Tibetan king Tridé Tsuktsen facilitated the cultural exchanges between Zang and Han nationalities to a new high, marking the heyday of cultural integration and reflecting the humanistic inclusiveness among ethnic groups. The mural painting of Playing Chess in Dunhuang grottoes could be regarded as a vivid demonstration of the influence of Go games on Tibetan chess in the Tang Dynasty. For an ethnic group, its prosperity is decided by the development level of its culture. Looking back into the past, the flourishing period of each dynasty is closely accompanied by the cultural thriving. Therefore, cultural exchanges could not only build unbreakable friendship among different ethnic groups, but also facilitate the harmony of collaborative development and common prosperity with mutual learning and mutual tolerance.

Chess playing is quite challenging for players, for its high demand for rigorous 
logical thinking. Each meticulously constructed move could change the whole situation at any moment. As to Square chess and Jiu chess, players are also expected to be with good volitional qualities, and follow the rule "Once touch the stone, move without regrets." Any hesitation about next move could be taken as the lack of confidence. In this way, playing Square chess and Jiu chess could promote the harmonious coexistence among different ethnic groups. In minority inhabited areas of northwest China as Gansu, Qinghai, Ningxia, and Xinjiang, people could gather in twos and threes to play chess in a lively atmosphere, regardless of ethnic group or age. Through mutual communication and mutual learning, people could promote the national feelings and pass the national spirit of being positive, enterprising, united and proactive.

To sum up, through comprehensive analysis of existing literature and the basic principles of Jiu chess, combined with the chess manual records of games in recent years, we could see that Jiu chess has very scientific playing rules. Keima (knight's move) in the endgame, with changeable features and unpredictable situations, could bring the obvious weaker side into a charming win. Jiu chess integrates into the unique and mysterious material and spiritual culture of Tibetan nationality, fully displaying the spirit, spiritual beliefs and lifelong pursuit for Tibetan people. So the promotion of Jiu chess and the classification of "Jiu" could be beneficial for the protection and inheritance of Tibetan chess.

Since the grading system of Jiu chess set up during the 2019 national Tibetan Chess Competition, Tibetan chess players can be graded along with the promotion of Grading Competitions. In Xinjiang, Square chess masters are known as "Gao Fang", who are not only best players, but also writers for books and papers on Xinjiang Square chess. In Ningxia, regional Square chess competitions have been held annually. Therefore, these traditional ethnic chess games in northwest areas, by the emphasis and assistance from local governments, could regenerate their new cultural values and enrich cultural life of these ethnic groups. Now, by entering the network age, Tibetan chess has been developed into game applications by universities like Tsinghua University, Minzu University of China, etc. it is believed that in the near future people can play these traditional ethnic chess games popular in northwest China through computers and mobile phones.

\section{Funding}

Project supported by National Social Science Fund, Research on Digital Protection and Inheritance of Endangered Minority Sports Culture Resources in Gansu and Qinghai Province; Grant No. 17BTY111.

\section{Conflicts of Interest}

The authors declare no conflicts of interest regarding the publication of this paper.

\section{References}

Dargye, P., \& Ding, L. H. (2012). On the Study and Protection of Tibetan Chess. Tibetan 
Studies, 1, 112-1176.

Han, C. D. (2011). Introduction to Square Chess of Hui Minority in Jingyuan County of Ningxia. Urban Tutor (Second Semimonthly), 4, 274.

Han, C. Y., \& Han, J. (2007). Summarization of History of the Non-Material Cultural Heritage “Xinjiang Square Chess". Sports Culture Guide, 9, 94-95.

Ma, S. L., \& Shang, T. (2017a). Inheritance and Protection of Tibetan Chess Culture. Tibetan Studies, 4, 157-160.

Ma, X. M., \& Shang, T. (2017b). A Comparative Study between Go and Tibetan Chess "Mimang". Journal of Qinghai Normal University (Philosophy and Social Sciences Edition), 4, 64-70.

Pan, Y. T., \& Ding, W. L. (2008). On the Cultural Connotations and Promotion Values of Square Chess as Traditional Folk Sports of Hui Minority. Journal of Hui Muslim Minority Studies, 4, 128-129.

Wang, P. (2013). Study on the Origin and Development of Square Chess as Ningxia Hui Minority's Traditional Sport. Contemporary Sports Technology, 34, 116-117. 